\title{
Maternity Clients Satisfaction with Client-Health Provider Interaction in State-owned Secondary Health Facilities in Cross River State
}

\author{
Felicia Ekwok Lukpata ${ }^{1}$, Ndukaku Nwakwue ${ }^{1}$, Hippolatus Ogar Lukpata ${ }^{2}$, Edum Tangban ${ }^{3}$, Chiamaka Rosemary \\ Anagor $^{4} \&$ Mary Achi Mgbekem ${ }^{1}$ \\ ${ }^{1}$ Department of Nursing Science, Faculty of Allied Medical Sciences, University of Calabar, Nigeria \\ ${ }^{2}$ Lutheran Hospital Yahe, Yala Local Government, Cross River State, Nigeria \\ ${ }^{3}$ Department of Nursing Science, Arthur Jarvis University, Akpabuyo, Cross River State, Nigeria \\ ${ }^{4}$ Department of Nursing Science, Faculty of Health Sciences and Technology, University of Nigeria, Enugu \\ Campus, Nigeria \\ Correspondence: Felicia Ekwok Lukpata, Department of Nursing Science, Faculty of Allied Medical Sciences, \\ University of Calabar, Cross River State, Nigeria. Tel: 234-805-103-5857. E-mail: fellylukpata@ymail.com
}

Received: July 12, 2020 Accepted: August 24, 2020 Online Published: October 19, 2020

doi:10.5539/gjhs.v12n12p53

URL: https://doi.org/10.5539/gjhs.v12n12p53

\begin{abstract}
Introduction: Satisfaction with care is a facilitator and major determinant of facility-based maternal healthcare utilization. It is therefore worrisome when maternity clients express dissatisfaction with any aspect of maternity care as this tend to discourage them from patronizing facility-based maternal services. This study examined Maternity Clients Satisfaction with Client-Health Provider interaction in State-owned Secondary Health Facilities in Cross River State.
\end{abstract}

Methods: The study adopted a cross-sectional survey design while a multistage sampling technique was used to select a sample population of 754 women of reproductive age found accessing maternal healthcare services in the studied facilities. A structured questionnaire was used to collect data and data obtained was analyse using descriptive techniques.

Result: Maternity clients were dissatisfied with the dimension of healthcare provider respect for clients as $321(42.6 \%)$ were dissatisfied and 133(17.6\%) were "very dissatisfied". Areas of dissatisfaction were health provider tone of voice, politeness and show of sympathy and support. However, clients were satisfied with healthcare provider provision of information as 234(31.0\%) were "very satisfied" and $225(29.8 \%)$ were "satisfied".

Conclusion: Based on the findings, it was concluded that respect for clients dimension of client-health provider interaction is a cause of dissatisfaction among maternity clients accessing care in State-Owned secondary health facilities. It was therefore recommended that stakeholders should make recruitment and retention of healthcare providers a priority as work overload affects interpersonal interactions. Also, update workshops on respectful maternity care should be organized at regular intervals for healthcare providers involved in maternity services.

Keywords: client-health provider interaction, maternity clients, provision of information, respect for clients

\section{Introduction}

Poor maternal health outcome has been a global challenge particularly in developing countries despite the implementation of various interventions. Evidence from studies shows that enhancing access and utilization of skilled maternal health services is key to achieving positive maternal health outcomes (Yayas et al., 2018; Cazottes, et al., 2014). An important facilitator and determinant to maternal healthcare service utilization is client satisfaction with care accessed in health facilities (Babalola \& Okafor, 2016). Manzoor, Wei, Hussain, Asif and Shah (2019) view client satisfaction as "a measure of the extent to which a patient is satisfied with the healthcare they received from their health care provider". In their view, Amu and Nyarko (2019) posit that satisfaction is an "experience that results from a subjective evaluation of what women expect to happen during their visit to the health facility and what they experienced during their visit" to the healthcare facilities. Women satisfaction with the care they receive from the facility acts as a criterion for improving the quality of maternal healthcare services 
(WHO, 2016).

The health workforce form the cornerstone of the healthcare system and their attitude determine satisfaction, access and utilization of healthcare services (Love, 2013; WHO, 2006). Despite the importance of health provider attitude to satisfaction, reports of negative and dysfunctional client-health provider interaction prevail such as; neglect of patient needs and concerns, inadequate provision of health information, verbal and physical abuse, ignoring or ridiculing patients, disrespect, lack of regard for privacy, unwillingness to accommodate traditional practices and authoritarian or frightening attitudes particularly in public healthcare facilities (Kwame \& Petrucka, 2020; Amu \& Nyarko, 2019; Norouzinia, Aghabarari, Shiri, Karimi, \& Samami, 2016; Mannava, Durrant, Fisher, Chersich \& Luchters, 2015). When healthcare providers show respects and politeness for clients, promptness of attention, cognitive care, competency, emotional support and provide necessary health information, client tend to be satisfied with care (Srivastava, Avan, Rajbangshi, \& Bhattacharyya, 2015). When healthcare providers do not render services in ways that meet the expectations of clients, the consequences manifest as dissatisfaction, failure to patronize the health facility and women preference for alternative and unskilled maternal healthcare (Amu \& Nyarko, 2019; Okonofua et al., 2017).

Respect for human dignity is a cornerstone of all nursing practices and a core nursing value. Globally, respect for clients accessing maternity care is attracting much attention and becoming a focus of discourse by experts and stakeholders in the field of reproductive health due to the negative consequences of disrespectful care (Ogunlaja et al., 2017). Some studies assert that the care maternity clients receive particularly in low-income countries have been characterized by disrespect, rudeness, shouting, abuse and fall short of the clients' expectations thus, generating dissatisfaction with maternal and child healthcare services (Ogunlaja et al., 2017; Rosen et al., 2015). Amu and Nyarko (2019) and Dzomeku (2011) outlined some aspects of disrespect reported by clients as; not listening to client explanation impoliteness in addressing clients, frowning, whispering, not explaining procedures, being shouted at, ignored and abandonment during periods of pains. Health provider lack of respect for client tends to negate efforts to reduce maternal mortality through access and availability of maternal health services as well as contribute to women preference for traditional birth attendants (TBAs) who are considered to be more respectful, empathic, compassionate than the healthcare professionals (Mannava et al., 2015; Love, 2013). Ojwang, Ogutu and Matu (2010) argue that disrespectful and impolite utterances hinder the "realization of other fundamental human rights and lead to violation of human dignity.

In a study by Ehiemere, Nwaneri, Iheanacho and Akpati (2011) reasons for dissatisfaction with nursing care as narrated by clients were "I don't like the way nurses address me" 37.5\%; "The nurses are harsh" $37.5 \%$. Findings by Amole, Tukur, Farouk, and Ashimi (2019) in Kano reveal that $55.9 \%$ of respondents agreed to have experienced at least one form of disrespect and abuse during maternity care while Population Council (2014) report that one in five women interviewed "report experiences of humiliation at some point of care during labour and delivery across thirteen (13) Kenyan health facilities". Conversely, some studies have reported satisfaction with healthcare providers respect and politeness. A study by Onasoga, Opiah, Osaji and Iwolisi (2012) shows that $77.5 \%$ respondents were warmly received by midwives during labour while Sufiyan, Umar and Shugaba (2013) also report that $60.3 \%$ of patients were satisfied with respect and reception. Asifere, Tessema and Tebeje (2018) assert that $70.8 \%$ of clients report satisfaction with support and respect for clients which was similar to the findings of Sapkota, Sapkota and Shrestha (2018) that $54.8 \%$ were satisfied with health providers' politeness, courtesy and respect for clients.

Providing clients with appropriate and adequate information concerning their health status, health maintenance and condition of the fetus or baby is important for healthy outcomes and enables clients to take responsibility for their health. Maternity women consider the provision of information by healthcare providers as being very important (Al-Ateeq \& Al-Rusaiess, 2015). Client-health provider interaction during care provides an opportunity for maternity clients to discuss their concerns and fears and clarify some unclear cultural beliefs and behaviour. Healthcare providers are also expected to provide adequate information on pregnancy, labour, postpartum, newborn care, breastfeeding, abnormal signs of pregnancy and appropriate actions to be taken (Al-Ateeq \& Al-Rusaiess, 2015). Provision of information enables the pregnant woman to be fully informed about the progress of her pregnancy, change harmful beliefs and behaviour and supports her to make informed decisions (Phommachanh, Essink, Wright, Broerse, \& Mayxay, 2019).

Despite the importance of adequate health information during pregnancy, most clients are not given such opportunities by healthcare providers to ask questions and clarify areas of confusion (Madula, Kalembo, Yu, Kaminga, 2018; Chavane, et al 2017). Asifere et al (2018) observed that only $45.2 \%$ of women report having the opportunity to ask questions with $54.7 \%$ of clients expressing dissatisfaction with providers' information provision. 
A focus group participant in Ajayi (2019) expressed "you will ask questions, and they will not answer and, they will look at your face as if you are not a human being". Saka, Yahaya and Saka (2012) observed that only $47.6 \%$ of the providers gave clear and accurate information. Similarly, Phommachanh, et al. (2019) argue that "provision of information on danger signs during pregnancy, nutrition, breastfeeding and iron supplements was insufficient" and "less than $10 \%$ of available health information materials" such as charts, posters and models were used during each ANC session.

However, assessing client satisfaction with antenatal care services, Sufiyan, et al (2013) observed that, 70.5\% of respondents were satisfied with healthcare provider explanations while $86.3 \%$ of patients had their questions answered. Also, Assefa, Mosse and Michael (2011) report that 51.7\% were satisfied with healthcare provider provision of information while Mocumbi et al (2019) also report that $94.3 \%$ were satisfied with answers given to the questions and $88.5 \%$ were satisfied with the clarity of information given.

\subsection{Statement of Problem}

There is a global concern on the low demand for facility-based maternity care with consequent poor maternal health outcome particularly in low-income countries (Okonofua, et al., 2017). The Africa Progress Panel 2010 opined that despite the effort invested by many countries to ensure availability of maternal health services, "the majority of women across Africa remain without full access to this care" (African Progress Panel, 2010). In Nigeria "less than $65 \%$ of pregnant women use health-facilities for antenatal services; fewer than $35 \%$ receive skilled birth attendance; while fewer than 65\% seek postnatal services" (Okonofua, et al 2017). In Cross River State, low utilization of healthcare facilities for skilled antenatal and delivery services has been a challenge (Omer, et al., 2014; Tulsi Chanri, 2013; Ugal, Ushie, Ushie \& Ingwu, 2012). Most women do not register for antenatal care and most of those who register prefer to deliver at home or with traditional birth attendants (Enang, et al., 2013). This trend has been attributed to several factors including dissatisfaction with the quality of maternal care received by women (Ajayi, 2019; Okonofua et al., 2017). Satisfying maternity clients is achieved by satisfying their needs and expectations (Al-Ateeq \& Al-Rusaiess, 2015).

The Cross River State Government introduced a cost-removal policy in 2009, under the umbrella of "PROJECT HOPE" where free maternal health services are provided (Edu, Agan, Monjok \& Makowiecka, 2017). However, the gains of free maternal services may dwindle fast if women are dissatisfied with services rendered. Some studies posit that even if services are available and the provider is skilled in managing complications, women may refuse to seek care when their experiences do not meet their expectations during interaction with healthcare providers (Bekele, Bayou \& Garedew, 2020; Shakibazadeh et al., 2017).

Evidence from studies implicates dysfunctional or negative client-health provider interaction such as disrespect and abuse, rudeness, failure to maintain privacy and confidentiality, inadequate provision of health information and lack of support for women during periods of pains (Ajayi, 2019; Phommachanh et al., 2019; Okonofua et al., 2017; Shakibazadeh et al., 2017). Dissatisfaction with maternity care is worrisome as it affects utilization and negates efforts towards improving maternal health outcomes. This concern gave impetus to this study which aimed at assessing maternity clients satisfaction with healthcare provider interaction in State-owned secondary healthcare facilities in Cross River State.

\subsection{Objectives}

Specifically, the study was designed to:

1) Assess maternity client satisfaction with health provider respect for clients in State-owned secondary health facilities in Cross River State

2) Investigate maternity client satisfaction with health provider provision of information in State-owned secondary health facilities in Cross River State

\subsection{Hypotheses}

1) There is no significant association between health provider respect for clients and satisfaction among maternity clients in State-owned secondary health facilities in Cross River State

2) There is no significant relationship between health provider provision of information and satisfaction among maternity clients in State-owned secondary health facilities in Cross River State

\section{Materials and Methods}

This study adopted a descriptive cross-sectional design considered suitable for this study. The study was a facility-based quantitative study carried out in Cross River State. Cross River State is located in the South-South 
geopolitical zone of Nigeria. The State has fifteen (15) State-owned secondary health facilities which are located in the urban and semi-urban areas of the State (Cross River State Ministry of Health, 2010). The study population consisted of women of reproductive age (15-49years) estimated to be 882,247 (Cross River State- Community Health Department, 2014). The criteria for eligibility include the population of women re-visiting the facilities for antenatal care, in-patients in the antenatal and postnatal ward as well as patients returning for postnatal services. The sample size for this study was determined using the Taro Yamane formula.

The formula is given as $n=\frac{N}{1+\left(N(e)^{2}\right.}$

Given that the population of women 15- 49 years in Cross River State is $=882,247$

$$
\begin{aligned}
& n=\frac{882,247}{1+\left(882247 \times(0.05)^{2}\right)} \\
& n=\frac{882247}{1+(882247 \times 0.0025)} \\
& n=\frac{882247}{1+2205.62}=\frac{882247}{2206.62}
\end{aligned}
$$

$\mathrm{n}=399.82$

$\mathrm{n}=400$

Note: The implication of this is that the sample size should not be less than 400 subjects but, to make room for non-bias response, the desired sample size was increased by $98 \%=792$.

A multistage sampling technique was adopted where the entire State was divided into three clusters with each senatorial zone representing a cluster; Southern, Central and Northern senatorial districts. Random sampling was used to select two secondary health facilities from each senatorial district giving a total of six (6) secondary health facilities. In each facility, convenience sampling was used to select one hundred and thirty-two (132) women of reproductive age found accessing maternal care.

The instruments for data collection was a structured questionnaire on a Likert scale with a test-retest reliability result of 0.60 . The questionnaire had two sections and was administered on a face to face basis by the researchers. Trained indigenous research assistants assisted non-literate women to enhance interpretation of the instrument items while others answered independently Seven hundred and fifty-four (754) questionnaires were valid and retrieved successfully. Data generated were prepared and analyzed using the statistical package for social sciences (SPSS) software 20.0 and results presented in percentages and tables. The research hypotheses were tested using the Pearson chi-square statistical technique.

A written application for the permission with an attached proposal for the study was sent to the State Health Research and Ethics committee. The approval letter was then presented to the management of each health facility. Verbal consent for participation was gotten from respondents before the administration of the research instrument. Confidentiality of responses was ensured. 


\section{Results}

Table 1. Socio-demographic data of Respondents. $\mathrm{N}=754$

\begin{tabular}{|c|c|c|c|}
\hline Statement & Variables & Respondents & Percentage (\%) \\
\hline \multirow{4}{*}{ Age } & $15-24$ years & 322 & 42.7 \\
\hline & $25-34$ years & 273 & 36.2 \\
\hline & $35-44$ years & 115 & 15.3 \\
\hline & 45 years and above & 44 & 5.8 \\
\hline Total & & 754 & 100 \\
\hline \multirow{2}{*}{ Marital status } & Married & 649 & 86.1 \\
\hline & Not married & 105 & 13.9 \\
\hline Total & & 754 & 100 \\
\hline \multirow{4}{*}{ Educational level } & No formal education & 58 & 7.7 \\
\hline & Primary & 210 & 27.9 \\
\hline & Secondary & 306 & 40.5 \\
\hline & Tertiary & 180 & 23.9 \\
\hline Total & & 754 & 100 \\
\hline \multirow{3}{*}{ Religion } & Christianity & 485 & 64.3 \\
\hline & Islam & 113 & 15 \\
\hline & Traditional & 156 & 20.7 \\
\hline Total & & 754 & 100 \\
\hline \multirow{4}{*}{$\begin{array}{l}\text { Number of visits to the facility for } \\
\text { MHS }\end{array}$} & Second visit & 368 & 48.8 \\
\hline & Third visit & 254 & 33.7 \\
\hline & Fourth visit & 93 & 12.3 \\
\hline & Fifth visit & 39 & 5.2 \\
\hline Total & & 754 & 100 \\
\hline \multirow{3}{*}{ Reason for the present visit } & Antenatal care & 427 & 56.6 \\
\hline & Delivery service & 273 & 36.2 \\
\hline & Postnatal care & 54 & 7.2 \\
\hline Total & & 754 & 100 \\
\hline
\end{tabular}

Table 1 shows the socio-demographic information of respondents. The result shows that most of the respondents $306(40.5 \%)$ had secondary education with only $58(7.7 \%)$ with no formal education. Majority 368(48.8\%) respondents were visiting the health facility for the second time while only $39(5.2 \%)$ were visiting for the fifth. Antenatal care had the highest clients 427 (56.6\%) while postnatal care services had the least number of clients $54(7.2 \%)$ 
Table 2. Responses on maternity clients' satisfaction with health provider respect for patients

\begin{tabular}{|c|c|c|c|}
\hline Statement & Response & Respondents & Percentage $(\%)$ \\
\hline Reception by provider & Very satisfied & 286 & 37.9 \\
\hline During clinic visits or & Satisfied & 190 & 25.2 \\
\hline \multirow[t]{2}{*}{ admissions } & Dissatisfied & 193 & 25.6 \\
\hline & Very dissatisfied & 85 & 11.3 \\
\hline Total & & 754 & 100 \\
\hline Politeness when addressing/ & Very satisfied & 180 & 23.9 \\
\hline communicating with & Satisfied & 101 & 13.4 \\
\hline \multirow[t]{2}{*}{ patients } & Dissatisfied & 263 & 34.9 \\
\hline & Very dissatisfied & 210 & 27.8 \\
\hline Total & & 754 & 100 \\
\hline Show of sympathy and & Very satisfied & 204 & 27.1 \\
\hline support during & Satisfied & 125 & 16.5 \\
\hline \multirow[t]{2}{*}{ pains } & Dissatisfied & 316 & 41.9 \\
\hline & Very dissatisfied & 109 & 14.5 \\
\hline Total & & 754 & 100 \\
\hline The tone of voice in giving & Very satisfied & 123 & 16.3 \\
\hline \multirow[t]{3}{*}{ Instruction } & Satisfied & 215 & 28.5 \\
\hline & Dissatisfied & 311 & 41.2 \\
\hline & Very dissatisfied & 105 & 13.9 \\
\hline Total & & 754 & 100 \\
\hline Overall satisfaction with & Very satisfied & 180 & 23.9 \\
\hline Health provider respect & Satisfied & 120 & 15.9 \\
\hline \multirow[t]{2}{*}{ for patient } & Dissatisfied & 321 & 42.6 \\
\hline & Very dissatisfied & 133 & 17.6 \\
\hline Total & & 754 & 100 \\
\hline
\end{tabular}

Responses on table 2 show respondents satisfaction with healthcare provider respect for maternity clients. Overall responses show that most clients $321(42.6 \%)$ were dissatisfied and $133(17.6 \%)$ were very dissatisfied while only $180(23.9 \%)$ and $120(15.9 \%)$ were very satisfied and satisfied respectively. The dimension of respect for patients that attracted the highest dissatisfied response was show of sympathy and support during pains with 316 (41.9\%) responses. However, client response on reception during the clinic visit shows that most clients 286 (37.9\%) were very satisfied with the reception given to them during clinic visits. 
Table 3. Responses on maternity client satisfaction with health provider provision of information

\begin{tabular}{|c|c|c|c|}
\hline Statement & Response & Respondents & Percentage (\%) \\
\hline Clarity and conciseness of & Very satisfied & 356 & 47.2 \\
\hline \multirow[t]{3}{*}{ information } & Satisfied & 202 & 26.8 \\
\hline & Dissatisfied & 139 & 18.4 \\
\hline & Very dissatisfied & 57 & 7.6 \\
\hline Total & & 754 & 100 \\
\hline Health provider patience in & Very satisfied & 103 & 13.7 \\
\hline \multirow[t]{3}{*}{ answering questions } & Satisfied & 120 & 15.9 \\
\hline & Dissatisfied & 380 & 50.4 \\
\hline & Very dissatisfied & 151 & 20.0 \\
\hline Total & & 754 & 100 \\
\hline Opportunity to ask question & Very satisfied & 224 & 29.7 \\
\hline \multirow[t]{3}{*}{ and clarify information } & Satisfied & 168 & 22.3 \\
\hline & Dissatisfied & 193 & 25.6 \\
\hline & Very dissatisfied & 169 & 22.4 \\
\hline Total & & 754 & 100 \\
\hline Use of information materials & Very satisfied & 248 & 33.0 \\
\hline Such as posters and models & Satisfied & 227 & 30.1 \\
\hline \multirow[t]{2}{*}{ during health talk } & Dissatisfied & 189 & 25.0 \\
\hline & Very dissatisfied & 90 & 11.9 \\
\hline Total & & 754 & 100 \\
\hline Maternity client satisfaction with health & Very satisfied & 234 & 31.0 \\
\hline provider provision of & Satisfied & 225 & 29.8 \\
\hline \multirow[t]{2}{*}{ information } & Dissatisfied & 171 & 22.7 \\
\hline & Very dissatisfied & 124 & 16.5 \\
\hline Total & & 754 & 100 \\
\hline
\end{tabular}

Table 3 shows responses to maternity clients' satisfaction with the healthcare provider provision of information. The overall satisfaction with health provider provision of information shows that 234(31.0\%) clients were very satisfied and $225(29.8 \%)$ were satisfied with health providers ability to provide the necessary health information to clients. The dimension of the provision of information that most satisfied the clients was clarity and conciseness of information with 356(47.2\%) and 202(26. 8\%) being very satisfied and satisfied respectively. Responses on clients opportunity to ask questions revealed that 224(29.7\%) respondents were very satisfied while $248(33.0 \%)$ were also very satisfied with health provider use of information materials such as posters. However, clients responses showed dissatisfaction with health provider patience in answering questions with $380(50.4 \%)$ and $151(20.0 \%)$ respondents being dissatisfied and very dissatisfied respectively.

\section{Discussion of Findings}

The sociodemographic data obtained in this study revealed that $40.5 \%$ of the respondents had secondary education. Interestingly, women with no formal education were only $7.7 \%$ indicating a moderate level of female literacy in the studied facilities catchment communities. This result may be related to the fact that secondary healthcare facilities are situated in urban and semi- urban areas where the female literacy level is not as dismal as seen in the rural areas where the burden of girl-child educational marginilisation is high.

Evidence from this study revealed maternity women dissatisfaction with respects for clients dimension of client-health provider interaction as $321(42.6 \%)$ respondent were dissatisfied while $133(17.6 \%)$ were very 
dissatisfied. Areas of dissatisfaction specifically were politeness, tone of voice, sympathy and support for clients. Healthcare provider disrespect for client observed in this study may be related to work overload experienced by health care professionals in State-owned health facilities influenced by the free maternal healthcare services. Work overload translates to stress which may manifest as disrespect, increase in tone of voice and impolite approach to clients. Again, when midwives are overwhelmed by the number of clients in labour which demand strict observation and documentation, they are left with no time to provide adequate emotional and verbal support for clients in pains. These findings suggest the utmost need for the State government to increase the population of the health workforce.

Dissatisfaction observed in this study collaborate the findings of Ehiemere, et al., (2011) who report that reason for dissatisfaction by $37.5 \%$ of clients was expressed as "I don't like the way nurses address me", "The nurses are harsh". However, this result disagrees with some studies who reported satisfaction with health provider respect for clients, politeness and support for clients (Sapkota, et al., 2018; Asifere, et al., 2018; Sufiyan, et al., 2013). This study further revealed that 286(37.9\%) respondents were very satisfied with the healthcare provider reception of clients. This tends to suggest that healthcare providers become disrespectful and harsh when they are overwhelmed with workload in the course of care consequently influencing their voice tone, sympathy and support for clients negatively. Satisfaction with reception agrees with the findings of Sufiyan, et al (2013) and Onasoga, et al (2012) who report that clients were satisfied with the warmth they received from providers.

Information on maternity client satisfaction with healthcare provider provision of information showed that 234(31.0\%) were very satisfied and 225(29.8\%) satisfied. This result buttresses the report by Assefa, et al (2011) who observed that $51.7 \%$ respondent were satisfied with healthcare provider provision of information. Results revealed satisfaction with clarity and conciseness of information, opportunity to ask questions as well as the use of information materials. This is consistent with the findings of some studies who report client satisfaction with the opportunity to ask questions, clarity of information, explanation and answers provided (Mocumbi et al., 2019; Umar \& Shugaba, 2013). These findings indicate a sound theoretical and practical knowledge-based of the healthcare providers involved in maternity care in Cross River State which enhanced their ability to provide health information clearly and concisely. Again, clarity of information provided portray the gains of Development Partners efforts in training and re-training of healthcare providers involved in maternity care in various areas of their interventions in Cross River State. Furthermore, satisfaction with clarity of information may be attributed to health provider use of posters, charts and models during health education sessions. However, this result contradicts the findings by Madula, et al (2018) and Chavane, et al (2017) who report that most clients were not given opportunity to ask questions and clarify areas of confusion.

The study further revealed that maternity clients were dissatisfied with provider patience in answering questions. Impatience in answering clients questions may be related to healthcare providers' cognizance of the large client attendance that characterizes maternal clinic days and their intention to prevent prolong waiting time considering the large attendance. However, there is need for healthcare providers to recognize individual differences in cognitive level and spend time in the repetition of necessary health information and clarify harmful beliefs. It is worthy of note here that, impatience reported in this study may deprive most clients of clarifying negative and confusing cultural beliefs that may be detrimental to maternal and fetal health. Clients loose-out on the gains of antenatal health sessions if hasty and shallow explanations are given to necessary health facts with consequent negative implication on maternal and fetal health outcome.

\section{Conclusion}

Client- health provider interaction is a major determinant of clients' satisfaction with maternity care. Despite its importance to satisfaction, challenges in client health provider interactions prevail in facility-based maternity care. This study revealed dissatisfaction in the dimension of health provider respect and politeness for maternity clients while responses showed satisfaction with healthcare provider provision of information except for provider impatient in answering client questions. These findings imply that poor maternal health outcomes may be the consequences of dissatisfaction with maternity care which can discourage utilization of facility-based skilled care with a preference for alternative care such as traditional birth attendants. There is, therefore, need for re-orientation of healthcare providers involved in maternity towards ensuring a functional client-health provider interaction to increase patronage of facility-based care if positive maternal outcome is to be achieved.

\subsection{Recommendations}

Based on the findings, the following recommendations were made;

1. The government and stakeholders in health should make recruitment and retention of healthcare providers a 
priority as work overload affect interactions and communications

2. Update workshops on respectful maternity care should be organized at regular intervals for healthcare providers involved in maternity services more so, with the increase in awareness of patients' rights

3. Healthcare providers particularly midwives theoretical and practical training should increase emphasis on the importance of therapeutic communication skills.

4. Again, the use of charts, models and posters during antenatal teaching should be encouraged as it enhance understanding.

5. Healthcare managers and administrators should develop and implement policies on disciplinary measures against reported cases of violation of clients respect and dignity.

\section{Acknowledgements}

The authors sincerely acknowledge the women who participated in this study.

\section{Funding Source}

None.

\section{Competing Interests Statement}

The authors declare that there are no competing or potential conflicts of interest.

\section{References}

African Progress Panel. (2010). Maternal health: Investing in the lifeline of healthy societies and economies. African Progress Panel Policy Brief, September 2010. Retrieved from http://www.who.int/pmnch/topics/maternal/app_maternal_health_english.pdf

Ajayi, A. I. (2019). "I am alive; my baby is alive": Understanding reasons for satisfaction and dissatisfaction with maternal health care services in the context of user fee removal policy in Nigeria. Plus one, 14(12), e0227010. https://doi.org/10.1371/journal.pone.0227010

Al-Ateeq, M. A., \& Al-Rusaiess, A. A. (2015). Health education during antenatal care: the need for more. International journal of women's health, 7, 239. https://doi.org/10.2147/IJWH.S75164

Amole, T. G., Tukur, M. J., Farouk, S. L., \& Ashimi, A. O. (2019). Disrespect and abuse during facility-based childbirth: The experience of mothers in Kano, Northern Nigeria. Tropical Journal of Obstetrics and Gynaecology, 36(1), 21-27. https://doi.org/10.4103/TJOG.TJOG_77_18

Amu, H., \& Nyarko, S. H. (2019). Satisfaction with Maternal Healthcare Services in the Ketu South Municipality, Ghana: A Qualitative Case Study. BioMed research international, 2019. https://doi.org/10.1155/2019/2516469.

Asifere, W. N., Tessema, M., \& Tebeje, B. (2018). Clients' satisfaction with health care providers' communication and associated factors among pregnant women attending antenatal care in Jimma town public health facilities, Jimma zone, southwest. Int $J$ Pregnancy Child Birth, 4(5), 223-230. https://doi.org/10.15406/ipcb.2018.04.00113

Assefa, F., \& Mosse, A. (2011). Assessment of clients' satisfaction with health service deliveries at Jimma University specialized hospital. Ethiopian Journal of health sciences, 21(2), 101-110. https://doi.org/10.4314/ejhs.v21i2.69050

Babalola, T. K., \& Okafor, I. P. (2016). Client satisfaction with maternal and child health care services at a public specialist hospital in a Nigerian Province. Turkish Journal of Public Health, 14(3). Retrieved from http://tjph.org/ojs/index.php/

Bekele, W., Bayou, N. B., \& Garedew, M. G. (2020). Magnitude of disrespectful and abusive care among women during facility-based childbirth in Shambu town, Horro Guduru Wollega zone, Ethiopia. Midwifery, 83, 102629. https://doi.org/10.1016/j.midw.2020.102629.

Cazottes, I., Costello, A., Davis, J., George, A., Houeto, D., Howard-Grabman, L., ... \& Persson, L. Å. (2014). WHO recommendation on community mobilization through facilitated participatory learning and action cycles with women' $s$ groups for maternal and newborn health. Retrieved from https://www.diva-portal.org/smash/record.jsf?pid

Chavane, L., Dgedge, M., Bailey, P., Loquiha, O., Aerts, M., \& Temmerman, M. (2017). Assessing women's satisfaction with family planning services in Mozambique. Journal of Family Planning and Reproductive 
Health Care, 43(3), 222-228. http://dx.doi.org/10.1136/jfprhc-2015-101190

Cross River State Community Health Department. (2014). CRSG PHC Programme Coordinated by Tulsi Chanri Foundation Facilities - Population Data.

Cross River State Ministry of Health. (2011). Cross River State Strategic Health Development Plan (2010 - 2015).

Dzomeku, M. V. (2011). Maternal satisfaction with care during labour: a case study of the Mampong-Ashanti district hospital maternity unit in Ghana. International Journal of Nursing and Midwifery, 3(3), 30-34. https://doi.org/10.5897/IJNM.9000029

Edu, B. C., Agan, T. U., Monjok, E., \& Makowiecka, K. (2017). Effect of free maternal health care program on health-seeking behaviour of women during pregnancy, Intrapartum and Postpartum Periods in Cross River State of Nigeria: A Mixed-Method Study. Open access Macedonian journal of medical sciences, 5(3), 370-382. https://doi.org/10.3889/oamjms.2017.075

Ehiemere, I O., Nwaneri, A., Iheanacho P., \& Akpati, V. (2011). Helpless patients satisfaction with the quality of nursing care in Federal tertiary hospitals, Enugu, Southeast, Nigeria. International journal of nursing and midwifery, 3(1), 6-13. https://doi.org/10.5897/IJNM.9000023

Enang, E., Ushie, M., Arikpo, I., Osonwa, K., Esu, E., Odey, F., ... \& Meremikwu, M. (2013). Childbirth practices in the Akpabuyo rural health and demographic surveillance system. Dev Ctry Stud, 3, 19-27. Retrieved from https://d1wqtxts1xzle7.cloudfront.net/31805598/

Kwame, A., \& Petrucka, P. M. (2020). Communication in nurse-patient interaction in healthcare settings in sub-Saharan Africa: A scoping review. International Journal of Africa Nursing Sciences, 12, 100198. https://doi.org/10.1016/j.ijans.2020.100198

Love, O. O. (2013). Experiences of women participating in a safe motherhood (Abiye) project in Ondo state of Nigeria. Int J Curr Microbiol App Sci, 2(12), 148-61. Retrieved from http://www.ijcmas.com/

Madula, P., Kalembo, F. W., Yu, H., \& Kaminga, A. C. (2018). Healthcare provider-patient communication: a qualitative study of women's perceptions during childbirth. Reproductive health, 15(1), 1-10. https://doi.org/10.1186/s12978-018-0580-x

Mannava, P., Durrant, K., Fisher, J., Chersich, M., \& Luchters, S. (2015). Attitudes and behaviours of maternal health care providers in interactions with clients: a systematic review. Globalization and health, 11(1), 36. https://doi.org/10.1186/s12992-015-0117-9

Manzoor, F., Wei, L., Hussain, A., Asif, M., \& Shah, S. I. A. (2019). Patient Satisfaction with Health Care Services; An Application of Physician's Behavior as a Moderator. International journal of environmental research and public health, 16(18), 3318. https://doi.org/10.3390/ijerph16183318

Mocumbi, S., Högberg, U., Lampa, E., Sacoor, C., Valá, A., Bergström, A., ... \& CLIP Working Group. (2019). Mothers' satisfaction with care during facility-based childbirth: a cross-sectional survey in southern Mozambique. BMC pregnancy and childbirth, 19(1), 303. https://doi.org/10.1186/s12884-019-2449-6

Norouzinia, R., Aghabarari, M., Shiri, M., Karimi, M., \& Samami, E. (2016). Communication barriers perceived by nurses and patients. Global journal of health science, 8(6), 65. https://doi.org/10.5539/gjhs.v8n6p65

Ogunlaja, A., Fehintola, O., Ogunlaja, I., Popoola, G., Idowu, A., Awotunde, O. T., \& Fehintola, O. F. (2017). Respectful Maternity Care" or "Disrespect and Abuse during Maternity Care"; Experience of pregnant women in Ogbomoso, South-West Nigeria. Rwanda Med. J, 74(3), 6-9. http://www.rwandamedicaljournal.org/

Ojwang, B. O., Ogutu, E. A., \& Matu, P. M. (2010). Nurses' impoliteness as an impediment to patients' rights in selected Kenyan hospitals. Health Hum Rights, 12(2), 101-17. Retrieved from https://www.hhrjournal.org

Okonofua, F., Ogu, R., Agholor, K., Okike, O., Abdus-Salam, R., Gana, M., ... \& Galadanci, H. (2017). Qualitative assessment of women's satisfaction with maternal health care in referral hospitals in Nigeria. Reproductive health, 14(1), 1-8. https://doi.org/10.1186/s12978-017-0305-6

Omer, K., Afi, N. J., Adamu, M., Malami, S. A., Oyo-Ita, A., Cockcroft, A., \& Andersson, N. (2014). Seeking evidence to support efforts to increase the use of antenatal care: a cross-sectional study in two states of Nigeria. BMC pregnancy and childbirth, 14(1), 380. https://doi.org/10.1186/s12884-014-0380-4

Onasoga, O. A., Opiah, M. M., Osaji, T. A., \& Iwolisi, A. (2012). Perceived effects of midwives attitude towards women in labour in Bayelsa State, Nigeria. Applied Science Research, 4(2), 960-964. Retrieved from 
http://www.scholarsresearchlibrary.com/

Phommachanh, S., Essink, D. R., Wright, E. P., Broerse, J. E., \& Mayxay, M. (2019). Do health care providers give sufficient information and good counselling during antenatal care in Lao PDR?: an observational study. $B M C$ health services research, 19(1), 449. https://doi.org/10.1186/s12913-019-4258-z

Population Council. (2014). Confronting Disrespect and Abuse during Childbirth in Kenya. The Heshima Project: Project Brief January. www.popcouncil.org.

Rosen, H. E., Lynam, P. F., Carr, C., Reis, V., Ricca, J., Bazant, E. S., \& Bartlett, L. A. (2015). Direct observation of respectful maternity care in five countries: a cross-sectional study of health facilities in East and Southern Africa. BMC pregnancy and childbirth, 15(1), 306. https://doi.org/10.1186/s12884-015-0728-4

Saka, M. J., Yahaya, L. A., \& Saka, A. O. (2012). Counselling and client provider-interactions as related to family planning services in Nigeria. $J$ Educ Pract, 3(5), 16-25. Retrieved From https://www.iiste.org/Journals/index.php/JEP/article/view/1494

Sapkota, D. K., Sapkota, M., \& Shrestha, K. B. (2018). Mothers' satisfaction on maternity Care Services in Bharatpur Hospital Chitwan, Nepal. Int. $J$ of Scientific and Research Publications, 8, 9. http://dx.doi.org/10.29322/IJSRP.8.9.2018.p8196

Shakibazadeh, E., Namadian, M., Bohren, M. A., Vogel, J. P., Rashidian, A., Nogueira Pileggi, V., ... \& Souza, J. P. (2018). Respectful care during childbirth in health facilities globally: a qualitative evidence synthesis. BJOG: An International Journal of Obstetrics \& Gynaecology, 125(8), 932-942. https://doi.org/10.1111/1471-0528.15015

Srivastava, A., Avan, B. I., Rajbangshi, P., \& Bhattacharyya, S. (2015). Determinants of women's satisfaction with maternal health care: a review of literature from developing countries. BMC pregnancy and childbirth, 15(1), 97. https://doi.org/10.1186/s12884-015-0525-0

Sufiyan, M. B., Umar, A. A., \& Shugaba, A. (2013). Client Satisfaction with Antenatal Care Services in Primary Health Care Centres in Sabon Gssari Local Government Area, Kaduna State Nigeria. Journal of Community Medicine and Primary Health Care, 25(1), 12-22. Retrieved from https://www.ajol.info/index.php/jcmphc/article/view/95510

Ugal, D. B., Ushie, B. A., Ushie, M., \& Ingwu, J. (2012). Utilization of Facilities and Maternal Health out care among urban dwellers of Obudu and Ogoja Local Government Area of Cross River State, Nigeria. Afro Asian Journal of Social Sciences, 3, 33. Retrieved from http://onlineresearchjournals.com/aajoss/art/96.

WHO. (2016). Standards for Improving Quality of Maternal and New Born Care in Health Facilities. WHO, Geneva, Switzerland. Retrieved from https://www.who.int/maternal child adolescent

Yaya, S., Okonofua, F., Ntoimo, L., Kadio, B., Deuboue, R., Imongan, W., \& Balami, W. (2018). Increasing women's access to skilled pregnancy care to reduce maternal and perinatal mortality in rural Edo State, Nigeria: a randomized controlled trial. Global Health Research and Policy, 3(1), 12. https://doi.org/10.1186/s41256-018-0066-y

\section{Copyrights}

Copyright for this article is retained by the author(s), with first publication rights granted to the journal.

This is an open-access article distributed under the terms and conditions of the Creative Commons Attribution license (http://creativecommons.org/licenses/by/4.0/). 